\title{
(2-Hydroxyethyl)ammonium Lactates-Highly Biodegradable and Essentially Non-Toxic Ionic Liquids
}

\author{
Sanita Pavlovica, Andris Zicmanis ${ }^{*}$, Elina Gzibovska, Maris Klavins, Peteris Mekss \\ Faculty of Chemistry, University of Latvia, Riga, Latvia \\ E-mail:"zicmanis@latnet.lv \\ Received June 28, 2011; revised July 30, 2011; accepted August 5, 2011
}

\begin{abstract}
(2-Hydroxyethyl)ammonium lactates have been prepared by reactions of the corresponding (2-hydroxyethyl) amines with lactic acid and characterized by their ${ }^{1} \mathrm{H}$ NMR, IR, and mass spectra. They have been quantitatively analyzed by HPLC, and their water contents have been determined by the Karl-Fischer method. The title salts are low-melting solids or viscous liquids, and they belong to the class of polar, hydrophilic ionic liquids. The toxicity and chemical and biological degradation of the synthesized ionic liquids have been evaluated by methods described in European Standards. The measurements showed these ionic liquids to be highly biodegradable and only slightly toxic substances. Condensation reactions of benzaldehyde with ethyl cyanoacetate and with acetophenone have been performed in these materials as solvents. The possibility of simultaneously applying these ionic liquids as both solvents and catalysts for the mentioned reactions has been demonstrated, as well as repeated use of the same ionic liquid for a number of condensation reactions without any purification.
\end{abstract}

Keywords: Ionic Liquids, Biodegradation, Toxicity, Polarity, Condensation Reactions

\section{Introduction}

Ionic liquids (ILs) have been widely and successfully exploited as solvents for organic synthesis during the last 20 years [1]. After their utilization, ILs tend to be disposed of to the environment and so pollute it. The most extensively used ILs, imidazolium and pyridinium salts, are toxic substances with a low biodegradation level. Although a great deal of research work has been directed towards elaborating ILs of low toxicity and high biodegradability during the last $5-10$ years, the results have as yet been modest. The obtained improvements in the quality of ILs have not been sufficient to permit their recommendation for safe exploitation in industrial processes without harming the environment. ILs of improved quality are needed both as solvents for organic transformations and as materials for other applications. Therefore, remarkably better materials than the hitherto used ILs, namely (2-hydroxyethyl)ammonium lactates, are proposed for the attention of specialists in this communication.

\section{Results and Discussion}

The cations of (2-hydroxyethyl)ammonium lactates $(\mathbf{2}, \mathbf{4}$,
6, 8) closely resemble that of choline [(2-hydroxyethyl) trimethylammonium hydroxide], which participates in human biological processes, while the anion, lactate, is a participant in the human metabolism process. It was expected that a combination of both ions might give a highly biodegradable and marginally toxic substances. Our preliminary experiments indicated that these expectations were valid. It looks that microorganisms decompose these new ILs in a substantially shorter time upon their release to the environment in comparison with other ammonium salts. Therefore (2-hydroxyethyl)ammonium lactates might serve as especially environmentally friendly ionic liquids.

(2-Hydroxyethyl)ammonium lactates are easily formed by the reaction of (2-hydroxyethyl)amines with lactic acid (Scheme 1). An $80 \%$ aqueous solution of L-(+)- lactic acid was used in our experiments, and the water liberated in the reaction as well as absorbed moisture was separated from the reaction mixture after the salt formation by distillation in vacuum followed by drying under high vacuum $\left(2\right.$ Torr, $\left.80^{\circ} \mathrm{C}\right)$. ILs $(\mathbf{2}, \mathbf{4}, \mathbf{6}, \mathbf{8})$ with different numbers of hydroxyl groups, and hence different polarities and hydrophilicities, were synthesized in this way. 


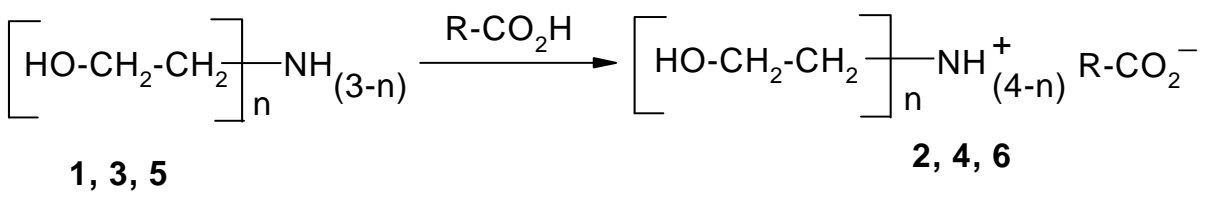

where: $\mathbf{1}, \mathbf{2}: \mathrm{n}=1 ; \mathbf{3}, \mathbf{4}: \mathrm{n}=2 ; \mathbf{5}, \mathbf{6}: \mathrm{n}=3$

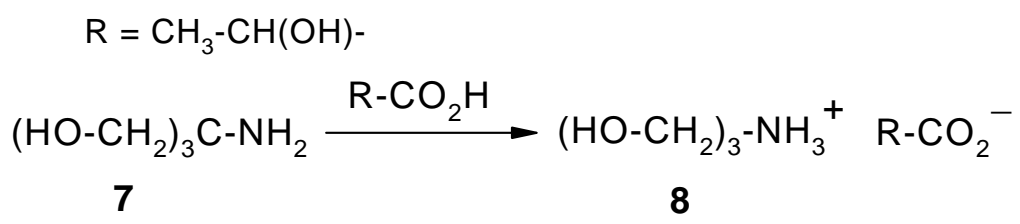

where: $\mathrm{R}=\mathrm{CH}_{3}-\mathrm{CH}(\mathrm{OH})$ -

Scheme 1. Synthesis of (2-hydroxyethyl)ammonium lactates.

The ILs were qualitatively analyzed by ${ }^{1} \mathrm{H}$ NMR and IR spectroscopies. The characteristic resonance signals in the ${ }^{1} \mathrm{H}$ NMR spectra are collected in Table 1. For the lactate anion, the signals of the methyl group protons $\left(\mathrm{CH}_{3}\right)$ can be found in the range $\delta(1.1-1.2 \mathrm{ppm})$, while that of the proton adjacent to the carboxylic group $(-\mathrm{C} \mathrm{H}(\mathrm{OH})-\mathrm{COO})$ appears in the range $\delta(3.7-3.9 \mathrm{ppm})$. The signals of the protons of the ammonium cation neighboring the oxygen atom can be found in the range $\delta$ (3.4 - $3.6 \mathrm{ppm}$ ), while those of the protons adjacent to the nitrogen atom can be found in the range $\delta(2.6-2.8$ ppm).

The IR spectra were less informative. Absorption bands at $v=(3500-3100), \sim 1750$, and $\sim 1600 \mathrm{~cm}^{-1}$ confirm only the presence of $\mathrm{OH}$ and $\mathrm{NH}$ groups, carboxylate anion, and ammonium cation in these materials. Hence, ${ }^{1} \mathrm{H}$ NMR and IR spectral data together certify the structures of the obtained ILs.

The ILs were quantitatively analyzed by HPLC/MS, using an instrument equipped with an MS as a detector. Only one signal was observed in each of the chromatograms, and mass spectrometry additionally confirmed the structures of the obtained ILs. In each case, the analyzed samples contained $\geq 98 \%$ of the IL according to HPLC/MS analysis.

The yields of the synthesized ILs were high ( $\geq 95 \%$ of isolated products), and the ILs were obtained as lowmelting solids or viscous liquids. Drying them in vacuum ensured a low water content $(\leq 2.0 \%)$ (Table 2). Fortunately, the presence of a minor amount of water in the ILs had practically no effect on our subsequently investigated condensation reactions.

The investigated ILs with the lactate anion and (2-hydroxyethyl)ammonium cations $(\mathbf{2}, \mathbf{4}, \mathbf{6}, \mathbf{8})$ were found to be less resistant to heating than other ILs. Their decomposition starts at $150^{\circ} \mathrm{C}$, and further degradation of the ILs follows immediately after the expulsion of the first water molecule at $\sim 150^{\circ} \mathrm{C}$ (Table 2). It means that the exploitation of described ionic liquids in syntheses is possible in a temperature range from room temperature to $\sim 120^{\circ} \mathrm{C}$. Fortunately, this temperature interval covers the greatest part of organic transformations. Organic syntheses in ILs are performed most frequently at room temperature and seldom above $100^{\circ} \mathrm{C}$. The mentioned above temperature limitation is justified by the fact that (2-hydroxyethyl)ammonium lactates are 2 - 3 times cheaper materials than other ILs.

The toxicity of the investigated ILs was also evaluated according to a standard method [10,11] using Brachionus calyciflorus, the lethal concentrations being appraised according to the described toxicity scale [17]. The measured lethal concentrations $\left(\mathrm{LC}_{50}\right)$ were $0.01-0.35$ $\mathrm{mol} / \mathrm{L}$ (Table 3). The results indicate that ILs 2, 4, 6, and 8 are practically non-toxic substances, their toxicity being $\sim 10$ times lower than that of ILs with imidazolium cations [17].

In order to evaluate the impact of the described ILs on the environment, their degradation was investigated by determining their chemical and biological oxygen demands. The chemical oxygen demand (chemical degradation) was measured according to the method described in the European Standard [13], and the obtained results are collected in Table 4. All investigated ILs have decomposed almost fully under these standard conditions, including very stable imidazolium and pyridinium salts. The biodegradation of our investigated ILs was also measured according to the relevant European Standard [14]. Compounds that attain a biodegradation level higher than $60 \%$ are considered to be easily biodegra-

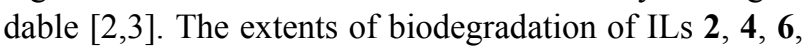
and 8 (Table 4) were found to be approximately $10-100$ 
Table 1. ${ }^{1} \mathrm{H}$ NMR spectra of the investigated ionic liquids.

\begin{tabular}{ccccccc}
\hline \multirow{2}{*}{ Entry } & $\mathrm{IL}$ & \multicolumn{5}{c}{${ }^{1} \mathrm{H} \mathrm{NMR}, \mathrm{ppm}$} \\
\cline { 3 - 7 } & $\mathbf{2}$ & $1.12(\mathrm{~d})$ & $-\mathrm{C} \underline{\mathrm{H}}-\mathrm{COO}_{3}-\mathrm{CH}-$ & $\underline{\mathrm{H}}-\mathrm{O}-, \underline{\mathrm{H}}-\mathrm{N}^{+}-$ & $\mathrm{O}_{-}-\underline{H}_{2}-$ & $\mathrm{N}-\underline{\mathrm{H}}_{2}-$ \\
\hline 1 & $\mathbf{4}$ & $1.14(\mathrm{~d})$ & $3.65(\mathrm{~m})$ & $5.40(\mathrm{~m})$ & $3.57(\mathrm{t})$ & $2.82(\mathrm{t})$ \\
2 & $\mathbf{6}$ & $1.20(\mathrm{~d})$ & $3.75(\mathrm{~m})$ & $5.05(\mathrm{~m})$ & $3.60(\mathrm{t})$ & $2.87(\mathrm{t})$ \\
3 & $\mathbf{8}$ & $1.13(\mathrm{~d})$ & $3.96(\mathrm{~m})$ & $4.30(\mathrm{~m})$ & $3.44(\mathrm{t})$ & $2.63(\mathrm{t})$ \\
4 & & $3.70(\mathrm{~m})$ & $5.21(\mathrm{~m})$ & $3.44(\mathrm{~s})$ & - \\
\hline
\end{tabular}

Table 2. Characteristics of the investigated ionic liquids.

\begin{tabular}{cccccccc}
\hline Entry & IL & Yield, $\%{ }^{\mathrm{a}}$ & Content of IL, $\%{ }^{\mathrm{b}}$ & m.p., ${ }^{\circ} \mathrm{C}$ & Water content, $\%^{\mathrm{c}}$ & $E_{T}^{N \mathrm{~d}}$ & Thermal stability, ${ }^{\circ} \mathrm{C}^{\mathrm{e}}$ \\
\hline 1 & $\mathbf{2}$ & 94 & $\geq 98$ & liquid & $1.8 \pm 0.4$ & 0.89 & 142 \\
2 & $\mathbf{4}$ & 97 & $\geq 98$ & liquid & $2.0 \pm 0.3$ & 0.93 & 157 \\
3 & $\mathbf{6}$ & 96 & $\geq 98$ & $45-46$ & $0.43 \pm 0.04$ & 1.00 & 152 \\
4 & $\mathbf{8}$ & 84 & $\geq 98$ & $105-110$ & $0.79 \pm 0.15$ & & 150 \\
\hline
\end{tabular}

${ }^{\mathrm{a}}$ Yield of the isolated product. ${ }^{\mathrm{b}}$ Analyzed by HPLC/MS. ${ }^{\mathrm{c}}$ Determined by the Karl-Fischer method. ${ }^{\mathrm{d}}$ Measured according to the described $[20]$ procedure. ${ }^{\mathrm{e}}$ The initial stage of the decomposition determined by thermogravimetry.

Table 3. Toxicity of (2-hydroxyethyl)ammonium lactates.

\begin{tabular}{ccc}
\hline Entry & IL & $\begin{array}{c}\text { Toxicity, } \\
\mathrm{LC}_{50}, \mathrm{~mol} / \mathrm{L}\end{array}$ \\
\hline 1 & $\mathbf{2}$ & $0.0101 \pm 0.0006$ \\
2 & $\mathbf{4}$ & $0.073 \pm 0.005$ \\
3 & $\mathbf{6}$ & $0.33 \pm 0.04$ \\
4 & $\mathbf{8}$ & $0.351 \pm 0.020$ \\
\hline
\end{tabular}

Table 4. Degradation of (2-hydroxyethyl)ammonium lactates.

\begin{tabular}{cccc}
\hline Entry & IL & $\begin{array}{c}\text { Biodegradation, } \\
\%^{\mathrm{a}}\end{array}$ & $\begin{array}{c}\text { Chemical } \\
\text { degradation, \% }\end{array}$ \\
\hline 1 & $\mathbf{2}$ & 95 & 98 \\
2 & $\mathbf{4}$ & 62 & 93 \\
3 & $\mathbf{6}$ & 60 & 92 \\
4 & $\mathbf{8}$ & 65 & 97 \\
5 & {$\left[\mathrm{C}_{12} \mathrm{mim}\right] \mathrm{Br}^{\mathrm{c}}$} & 6 & 97 \\
6 & {$\left[\mathrm{C}_{12} \mathrm{py}_{\mathrm{Br}}^{\mathrm{c}}\right.$} & 10 & 95 \\
7 & {$\left[\right.$ Hmim lactate $[5]_{8}$} & 5 & \\
8 & Reference material $^{\mathrm{c}}$ & 99 & \\
\hline
\end{tabular}

${ }^{a}$ Determined according to [14], expressed as the ratio of biological and chemical oxygen demands, with the concentration of IL $2 \mathrm{mg} / \mathrm{L}$. ${ }^{b}$ Determined according to the Standard [13], expressed as the ratio of experimental and theoretical chemical oxygen demands, with the concentration of IL 2 $\mathrm{mg} / \mathrm{L}$ in experiments. ${ }^{\mathrm{c}}$ Abbreviations: $\left[\mathrm{C}_{12} \mathrm{mim}\right]$ : 1-dodecyl-3-methylimidazolium; [ $\mathrm{C}_{12}$ py]: 1-dodecylpyridinium; [Hmim]: 1-methylimidazolium; reference material: a mixture of glucose and glutamic acid.

times higher than those of common ILs [22], including N-methyl imidazolium lactate [5]. The highest biodegradation level (95\%) was found for (2-hydroxyethyl) ammonium lactate (2). The other ILs have biodegradation levels $\geq 60 \%$, indicating that they also decompose relatively easily. It should be emphasized that a mixture of glucose and glutamic acid was used as a reference material in our measurements; its biodegradation was 99\% complete when measurements were made in exactly the same way in which our ILs were tested, with an incubation period of 5 days. Therefore, the synthesized (2-hydroxyethyl)ammonium lactates may be considered as environmentally friendly solvents and exceptionally harmless materials.

The investigated ILs (2, 4, 6, and 8) contain several $\mathrm{O}-\mathrm{H}$ and $\mathrm{N}-\mathrm{H}$ bonds and are therefore both highly hydrophilic materials and considerably polar solvents. Their polarity was estimated according to Reichardt's polarity index $\left(E_{T}^{N}\right)$, measured as proposed by Reichardt himself [20]. The determined polarities of our ILs are quite close to that of water $\left(E_{T}^{N}=1.00\right)$; the index values lie in an interval between 0.89 and 1.00 (Table 2).

The effectiveness of the proposed ILs as reaction media was tested by carrying out two Knoevenagel condensation reactions: reaction of benzaldehyde (9) with ethyl cyanoacetate (10) and that of benzaldehyde (9) with acetophenone (12) (Scheme 2). The results were compared with those obtained in ethanol solution (Table 5).

The condensation of benzaldehyde with ethyl cyanoacetate proceeded easily, and yields of the product (11) were high. The addition of glycine as an extra catalyst led to only an insignificant increase in the yield (Table 5). The results were unsurprising because our ILs themselves are ammonium salts, substances that are similar to ammonium acetate, the most frequently exploited catalyst in these Knoevenagel condensation reactions.

The hydrophilicity of ILs and the size of their cations increase with increasing number of 2-hydroxyethyl groups that they bear. Cations are moved further away 


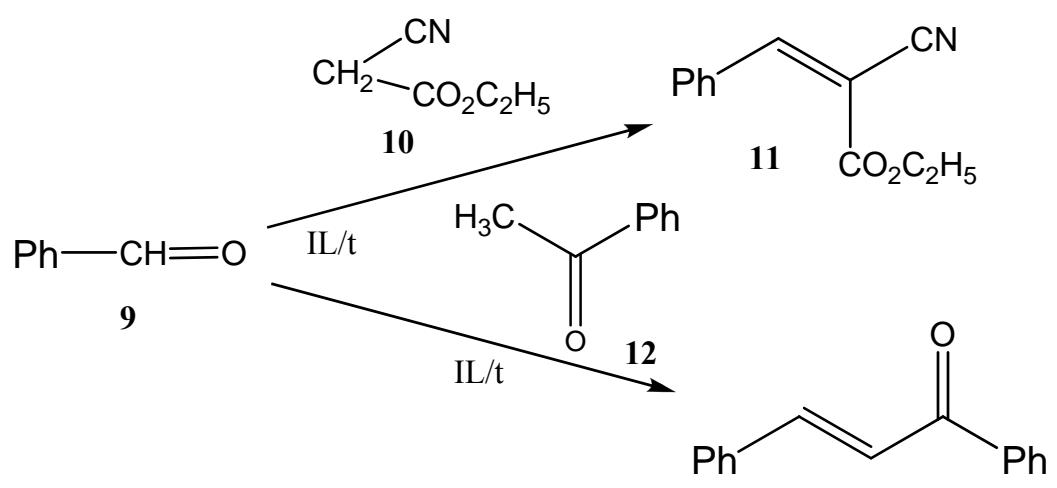

13

Scheme 2. Condensation reactions in ionic liquids-(2-hydroxyethyl)ammonium lactates.

Table 5. Yields of condensation reaction products in ionic liquids and ethanol.

\begin{tabular}{|c|c|c|c|c|c|c|}
\hline \multirow{3}{*}{ Entry } & \multirow{3}{*}{ IL } & \multicolumn{5}{|c|}{ Yield, $\%^{\mathrm{a}}$} \\
\hline & & \multicolumn{2}{|c|}{11} & \multicolumn{3}{|c|}{13} \\
\hline & & $1 \mathrm{~h} / 90^{\circ} \mathrm{C}$ & $1 \mathrm{~h} / 90^{\circ} \mathrm{C}^{\mathrm{b}}$ & $6 \mathrm{~h} / 100^{\circ} \mathrm{C}$ & $12 \mathrm{~h} / 100^{\circ} \mathrm{C}$ & $24 \mathrm{~h} / 100^{\circ} \mathrm{C}$ \\
\hline 1 & 2 & 83 & 72 & 65 & 90 & 95 \\
\hline 2 & 4 & 94 & 89 & 43 & 73 & 93 \\
\hline 3 & 6 & 88 & 90 & 0 & 0 & 0 \\
\hline 4 & 8 & 84 & 90 & 3 & 10 & 10 \\
\hline 5 & EtOH & 34 & $89^{\mathbf{c}}$ & $74^{\mathrm{d}}$ & 75 & 85 \\
\hline
\end{tabular}

${ }^{a}$ Yield of the isolated condensation reaction product containing $\geq 99.0 \%$ of the base stock (by GC-MS) using the molar ratio benzaldehyde: ethyl cyanoacetate (acetophenone): ionic liquid = 1:1:2. ${ }^{b}$ Yield of the product using glycine as a catalyst and the molar ratio benzaldehyde: ethyl cyanoacetate: ionic liquid: glycine $=1: 1: 2: 1$. ${ }^{\mathrm{c}}$ Yield in ethanol in the presence of glycine as a catalyst according to a described [15] procedure. ${ }^{\mathrm{d}}$ Yield in a 1:1 water/ethanol mixture in the presence of $\mathrm{NaOH}$ as a catalyst according to a described [16] procedure.

from their lactate anion in ILs with a larger number of 2-hydroxyethyl groups. The best yields of the product 11 were achieved in ILs 4 and $\mathbf{6}$ (Table 5), and the observed results validate the frequently expressed idea about the necessity and possibility of designing an IL of optimal structure for every particular reaction [1].

The condensation of benzaldehyde with acetophenone (acetylbenzene) proceeded considerably less readily than that with ethyl cyanoacetate, and more severe reaction conditions were necessary to obtain acceptable yields of the product (13), $24 \mathrm{~h}$ at $100^{\circ} \mathrm{C}$ in the best ILs (Figure 1).

Condensation reactions are affected by the acidity of the medium, and optimal $\mathrm{pH}$ is needed for every reaction. $\mathrm{pH}$ values have no meaning in water-free ILs; however, it is possible to measure or estimate $\mathrm{pH}$ values of aqueous solutions of the investigated ILs. The fact that the polarities of the ILs $\left(E_{T}^{N}=0.89-1.00\right.$, Table 2) are close to that of water $\left(E_{T}^{N}=1.00\right)$ justifies such an approximation.

Our experiments have shown that increased hydrophilicity (and polarity) of the ILs decreases the yield of the condensation reaction product $(\mathbf{1 3})$, such that the yields decrease in the sequence $2>\mathbf{4}>\mathbf{8}>\mathbf{6}$. A prolonged reaction time of up to $24 \mathrm{~h}$ resulted in high yields only in ILs 2 and 4; yields in IL 8 slowly increased with time, but the reaction did not proceed at all in IL 6 (Figure 1, Table 5).

The rates and yields of condensation reactions in common solvents (molecular liquids) usually depend on the acidity level of the reaction medium. To evaluate the possible impact on the same reactions in ILs, the condensation reaction between benzaldehyde and acetophenone was tested in various ILs that differ in their $\mathrm{pH}$ values in aqueous solution. As ILs are highly polar solvents, one might assume that the acidities of substances in IL media might show similar trends to those in water, even though measuring such pseudo-pH values is not meaningful. To check this idea, yields of 1,3-diphenylpropen-1-one $(\mathbf{1 3})$ (after $24 \mathrm{~h}$ at $100^{\circ} \mathrm{C}$ ) in ILs with different $\mathrm{pH}$ values in aqueous solution were compared. The results confirmed that high product yields could only be achieved in a very narrow range of pseudo- $\mathrm{pH}$ values, 6.4 - 6.7 (Figure 2).

The polarities of common solvents (molecular liquids) also have an impact on the results of condensation reactions. The polarities of the investigated (and other) ILs have been characterized by different criteria, most frequently by their Reichardt's constants, $E_{T}^{N}$ values. Again, the yields of 1,3-diphenylpropen-1-one (13) un- 


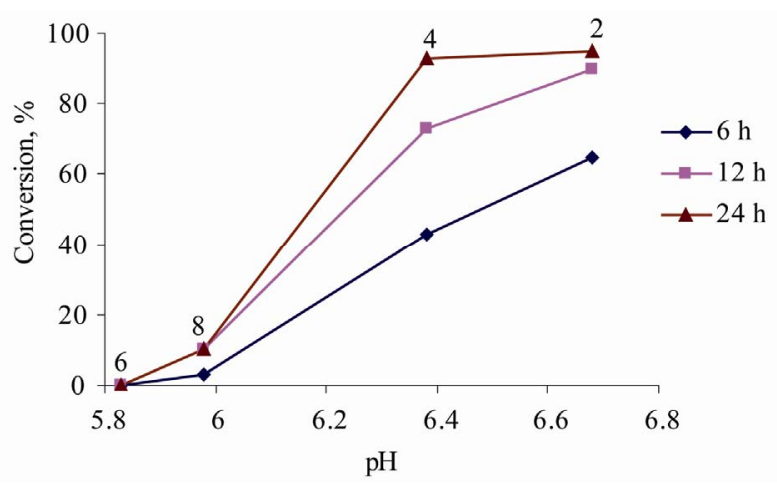

Figure 1. Impact of the reaction time and acidity of the medium on the yield of 1,3-diphenylpropen-1-one (13) in different (2-hydroxyethyl)ammonium lactates $(2,4,6,8)(\mathrm{pH}$ of $0.10 \mathrm{~mol} / \mathrm{L} \mathrm{ILs}$ in aqueous solutions).

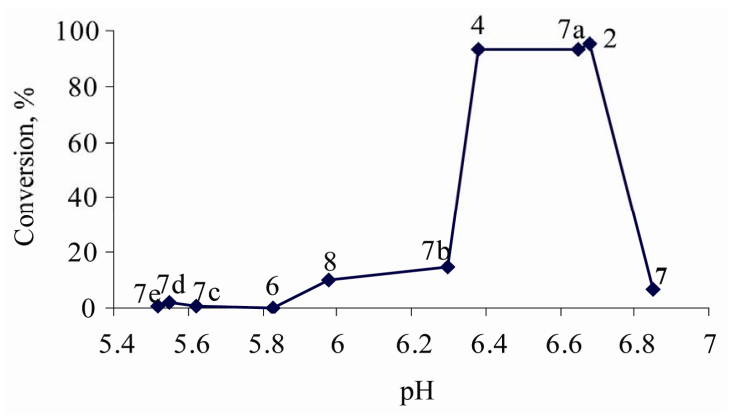

Figure 2. Impact of the acidity of aqueous solutions of ionic liquids on the yield of 1,3-diphenylpropen-1-one (13) (after $24 \mathrm{~h}$ at $100^{\circ} \mathrm{C}$, where $2,4,6$, and 8 are the abovementioned (2-hydroxyethyl)ammonium lactates; 7: bis(2-hydroxyethyl) ammonium acetate; 7a: (2-hydroxyethyl)ammonium formate; 7b: tris(2-hydroxyethyl)ammonium acetate; 7c: butylmethylimidazolium bromide; 7d: methylimidazolium lactate; $7 \mathrm{e}$ : methylimidazolium formate.

der similar reaction conditions (after $24 \mathrm{~h}$ at $100^{\circ} \mathrm{C}$ ) in ILs of various Reichardt's constants were compared. The highest yields of the product (13) were again obtained only in a rather narrow polarity region $\left(E_{T}^{N}=0.89-0.93\right)$ (Figure 3). Consequently, the polarity of the ILs substantially affects the outcomes of condensation reactions performed in them.

The condensation reaction product is usually isolated from the reaction mixture in one of two ways: 1) by dissolving the IL in water and separating the product; 2) by extracting the product from the reaction mixture with some organic solvent (diethyl ether, benzene, etc.) and then evaporating the solvent. The second method allows repeated exploitation of the same IL several times. Our experiments have shown that high yields $(\geq 95 \%)$ of the product (11) may be repeatedly obtained from the condensation of benzaldehyde with ethyl cyanoacetate in the same IL, up to twenty times without any purification of the IL (Table 6).

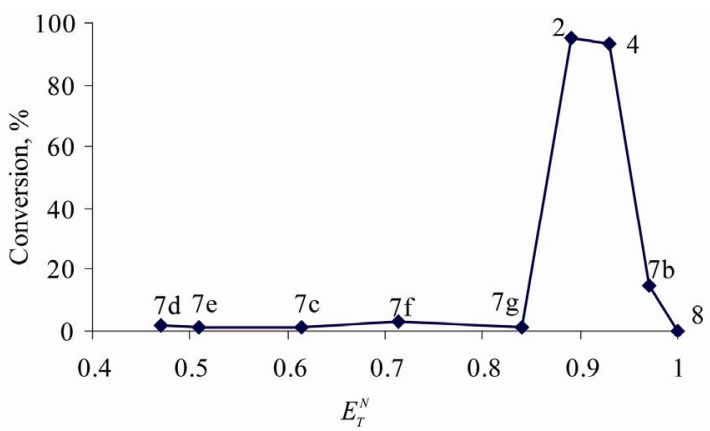

Figure 3. Impact of the polarity of ionic liquids on the yield of 1,3-diphenylpropen-1-one (13) (after $24 \mathrm{~h}$ at $100^{\circ} \mathrm{C}$ ), where 2, 4, and 8 are the abovementioned (2-hydroxyethyl) ammonium lactates; 7: bis(2-hydroxyethyl)ammonium acetate; 7b: tris(2-hydroxyethyl)ammonium acetate; 7c: butylmethylimidazolium bromide; 7d: methylimidazolium lactate; 7e: methylimidazolium formate; $7 \mathrm{f}$ : ethylmethylimidazolium methanesulfonate; $7 \mathrm{~g}$ : heptylpyridinium bromide.

The repeated utilization of ILs is only advantageous for reactions from which the product is separated by extraction with an organic solvent. The latter is partly distilled off after the extraction, which allows solid products to be crystallized simultaneously (from the solvent of the extraction). Therefore, (2-hydroxyethyl) ammonium lactates may be considered as very promising solvents for condensation reactions that require a highly hydrophilic medium and the presence of catalysts with acidic and basic properties.

\section{Conclusions}

(2-Hydroxyethyl)ammonium lactates are highly biodegradable and practically non-toxic ionic liquids. Condensation reactions proceed rapidly in these media, giving high yields of products without any other catalyst, and it is possible to reuse the same ionic liquid repeatedly for at least twenty times. The polarity and pseudo- $\mathrm{pH}$ of ionic liquids substantially affect the rates and yields of condensation reactions of aromatic aldehydes with activated methyl- or methylene compounds performed therein.

\section{Experimental}

\subsection{Materials}

L-(+)-Lactic acid (80\%), 2-aminoethanol, 2- $N$-(2-hydroxyethyl)aminoethanol, and 2-N,N-bis(2-hydroxyethyl) aminoethanol (Aldrich) were distilled in vacuum before use. All other chemicals were analytical grade commercial products (Aldrich).

\subsection{Syntheses of Ionic Liquids}

(2-Hydroxyethyl)ammonium lactate (2): An aqueous 
Table 6. Yields of the product in repeated condensation reactions of benzaldehyde with ethyl cyanoacetate in the same IL, bis(2-hydroxyethyl)ammonium lactate.

\begin{tabular}{ccccccccc}
\hline Entry & Run & Yield $^{\mathrm{a}} \%$ & Entry & Run & Yield $^{\text {a }} \%$ & Entry & Run & Yield ${ }^{\text {a }} \%$ \\
\hline 1 & 1 st & 94 & 8 & 8 th & 99 & 15 & 15 th & 99 \\
2 & 2nd & 95 & 9 & 9 th & 98 & 16 & 16 th & 96 \\
3 & 3rd & 99 & 10 & 10 th & 96 & 17 & 17 th & 99 \\
4 & 4 th & 93 & 11 & 11 th & 98 & 18 & 18 th & 95 \\
5 & 5 th & 96 & 12 & 12 th & 98 & 19 & 19 th & 96 \\
6 & 6th & 96 & 13 & 13 th & 97 & 20 & 20 th & 95 \\
7 & 7 th & 95 & 14 & 14 th & 97 & 21 & 21 st & 94 \\
\hline
\end{tabular}

${ }^{\mathrm{a}}$ Yield of the isolated condensation reaction product (11) (base stock $\geq 99.0 \%$ by GC-MS) after $1 \mathrm{~h}$ at $90^{\circ} \mathrm{C}$ in $\mathrm{IL} 4$; molar ratio benzaldehyde: ethyl cyanoacetate: ionic liquid $=1: 1: 2$.

solution of L-(+)-lactic acid (19.26 g, $171.0 \mathrm{mmol})$ was added dropwise to (2-hydroxyethyl)amine (10.45 g, $171.0 \mathrm{mmol}$ ) at $0^{\circ} \mathrm{C}$ over a period of $\sim 1 \mathrm{~h}$ with vigorous stirring, keeping the temperature at $0^{\circ} \mathrm{C}-5^{\circ} \mathrm{C}$. Following the addition, stirring was continued for $30 \mathrm{~h}$ at room temperature. Water was distilled off from the reaction mixture in vacuum (10 - 15 Torr). The obtained viscous mass was dried in vacuum $\left(2-3\right.$ Torr, $\left.60^{\circ} \mathrm{C}-80^{\circ} \mathrm{C}\right)$ for $12 \mathrm{~h}$ to afford $24.31 \mathrm{~g}(94 \%)$ of the product (2) in the form of a viscous liquid. ${ }^{1} \mathrm{H}$ NMR spectrum (DMSO- $\mathrm{d}_{6}$, $\delta, \mathrm{ppm}): 1.12\left(\mathrm{~d}, 3 \mathrm{H}, \mathrm{CH}_{3}-\mathrm{CH}\right) ; 2.82\left(\mathrm{t}, 2 \mathrm{H}, \mathrm{CH}_{2}-\mathrm{N}\right)$; 3.57 (t, $\left.2 \mathrm{H}, \mathrm{CH}_{2}-\mathrm{O}\right) ; 3.65\left(\mathrm{~m}, 1 \mathrm{H},-\mathrm{CH}_{-}-\mathrm{COO}^{-}\right) ; 5.40(\mathrm{~m}$, $\left.4 \mathrm{H}, \mathrm{NH}_{3}+\underline{\mathrm{OH}}\right)$. IR spectrum (Nujol, v, $\mathrm{cm}^{-1}$ ): $3700-$ $3000(\mathrm{~N}-\mathrm{H}+\mathrm{O}-\mathrm{H}) ; 1750-1600(\mathrm{C}=\mathrm{O}+\mathrm{N}-\mathrm{H})$.

Other ionic liquids were prepared in a similar way.

Bis(2-hydroxyethyl)ammonium lactate (4): A viscous liquid, yield 97\%; ${ }^{1} \mathrm{H}$ NMR spectrum (DMSO- $d_{6}, \delta$, ppm): 1.14 (d, 3H, $\left.\underline{\mathrm{CH}}_{3}-\mathrm{CH}\right) ; 2.87$ (t, 4H, $\left.\underline{\mathrm{CH}}_{2}-\mathrm{N}\right) ; 3.60$ $\left(\mathrm{t}, 4 \mathrm{H}, \mathrm{CH}_{2}-\mathrm{O}\right) ; 3.75\left(\mathrm{~m}, 1 \mathrm{H}, \mathrm{CH}-\mathrm{COO}^{-}\right) ; 5.05(\mathrm{~m}, 4 \mathrm{H}$, $\mathrm{NH}_{3}+\mathrm{O} \underline{\mathrm{H}}$ ). IR spectrum (Nujol, $\left.v, \mathrm{~cm}^{-1}\right): 3700-3000$ $(\mathrm{N}-\mathrm{H}+\mathrm{O}-\mathrm{H}) ; 1750-1600(\mathrm{C}=\mathrm{O}+\mathrm{N}-\mathrm{H})$.

Tris(2-hydroxyethyl)ammonium lactate (6): A white solid, m.p. $45^{\circ} \mathrm{C}-46^{\circ} \mathrm{C}$, yield $96 \%$. ${ }^{1} \mathrm{H}$ NMR spectrum (DMSO- $\left.d_{6}, \delta, \mathrm{ppm}\right): 1.20$ (d, 3H, $\left.\mathrm{CH}_{3}-\mathrm{CH}-\right) ; 2.63$ (t, 2H, $\left.\mathrm{C}_{2}-\mathrm{N}\right) ; 3.44$ (t, 2H, $\left.\underline{\mathrm{H}}_{2}-\mathrm{O}\right) ; 3.96$ (m, 1H, $\underline{\mathrm{H}}_{-}-\mathrm{COO}^{-}$); $4.30\left(\mathrm{~m}, 4 \mathrm{H}, \mathrm{N}_{3}+\mathrm{OH}\right)$.

Tris(2-hydroxymethyl)methylammonium lactate (8): A white solid, m.p. $105^{\circ} \mathrm{C}-110^{\circ} \mathrm{C}$, yield $84 \%$. ${ }^{1} \mathrm{H}$ NMR spectrum (DMSO- $\left.d_{6}, \delta, \mathrm{ppm}\right): 1.13\left(\mathrm{~d}, 3 \mathrm{H}, \mathrm{CH}_{3}-\mathrm{CH}\right)$; $3.44\left(\mathrm{~s}, 6 \mathrm{H}, \mathrm{CH}_{2}-\mathrm{O}\right) ; 3.70\left(\mathrm{~m}, 1 \mathrm{H}, \mathrm{CH}_{-}-\mathrm{COO}^{-}\right) ; 5.21(\mathrm{~m}$, $\left.6 \mathrm{H}, \mathrm{NH}_{3}+\mathrm{OH}\right)$. IR spectrum (Nujol, $\left.v, \mathrm{~cm}^{-1}\right): 3700-$ $3000(\mathrm{~N}-\mathrm{H}+\mathrm{O}-\mathrm{H}) ; 1750-1600(\mathrm{C}=\mathrm{O}+\mathrm{N}-\mathrm{H})$.

\subsection{Condensation Reactions in Ionic Liquid Media}

Ethyl 2-cyano-3-phenylpropenoate (11): Benzaldehyde (0.53 g, $5.0 \mathrm{mmol})$, ethyl cyanoacetate $(0.57 \mathrm{~g}, 5.0 \mathrm{mmol})$, and bis(2-hydroxyethyl)ammonium lactate $(4,1.95 \mathrm{~g}$,
$10.0 \mathrm{mmol}$ ) were stirred at $90^{\circ} \mathrm{C}$ for $1 \mathrm{~h}$. The reaction mixture was then cooled to room temperature and extracted with diethyl ether $(5 \times 4 \mathrm{~mL})$. The combined ethereal extracts were washed with water $(2 \times 2 \mathrm{~mL})$, dried over sodium sulfate for $16 \mathrm{~h}$, and concentrated to dryness. The residue was crystallized from ethanol. Colorless product (11) was obtained $(0.94 \mathrm{~g}, 94 \%)$ with m.p. $52^{\circ} \mathrm{C}-53^{\circ} \mathrm{C}$ (lit. [15] m.p. $51^{\circ} \mathrm{C}-53^{\circ} \mathrm{C}$ ). ${ }^{1} \mathrm{H}$ NMR spectrum (DMSO- $\left.d_{6}, \delta, \mathrm{ppm}\right): 8.13(\mathrm{~s}, 1 \mathrm{H}, \underline{\mathrm{H}}-\mathrm{C}=) ; 7.79$ $7.33\left(\mathrm{~m}, 5 \mathrm{H}, \underline{\mathrm{H}}-\mathrm{C}_{\mathrm{Ar}}\right) ; 4.23\left(\mathrm{t}, 2 \mathrm{H}, \mathrm{CH}_{2}-\mathrm{O}\right) ; 1.42$ (q, $3 \mathrm{H}$, $\left.\mathrm{CH}_{2}-\underline{\mathrm{CH}}_{3}\right)$.

Condensation reactions in the other ILs 2, 6, and 8 were performed in a similar way. The repeated syntheses in the same IL were also performed in a similar way, without any purification of the IL between the runs. The results are presented in Tables 5 and $\mathbf{6}$.

1,3-Diphenylprop-2-en-1-one (benzalacetophenone, 13): Benzaldehyde $(0.53 \mathrm{~g}, 5.0 \mathrm{mmol})$, acetophenone $(0.60 \mathrm{~g}$, $5.0 \mathrm{mmol})$, and (2-hydroxyethyl)ammonium lactate (2, $1.51 \mathrm{~g}, 10.0 \mathrm{mmol}$ ) were stirred at $100^{\circ} \mathrm{C}$ for $24 \mathrm{~h}$. The reaction mixture was cooled to $75^{\circ} \mathrm{C}$ and extracted with boiling benzene $(5 \times 10 \mathrm{~mL})$. The combined benzene extracts were washed with water $(2 \times 2 \mathrm{~mL})$, dried over sodium sulfate for $16 \mathrm{~h}$, and concentrated to dryness. The residue was crystallized from ethanol. Yellow product (13) was obtained $(0.98 \mathrm{~g}, 95 \%)$ with m.p. $56^{\circ} \mathrm{C}-57^{\circ} \mathrm{C}$ (lit. [21] m.p. $\left.56^{\circ} \mathrm{C}-57^{\circ} \mathrm{C}\right) .{ }^{1} \mathrm{H}$ NMR spectrum (DMSO-d $\left.{ }_{6}, \delta, p p m\right): 6.06(\mathrm{~d}, 1 \mathrm{H}, \underline{\mathrm{H}}-\mathrm{C}=) ; 5.83(\mathrm{~d}, 1 \mathrm{H}$, $\underline{\mathrm{H}}-\mathrm{C}=) ; 5.75-5.54$ (m, $10 \mathrm{H}, \underline{\mathrm{H}}-\mathrm{Ar})$.

Condensation reactions in the other ILs $\mathbf{4}, \mathbf{6}$, and 8 were performed in a similar way. The results are collected in Table 5 and shown in Figures 1-3.

\subsection{Measurements}

${ }^{1} \mathrm{H}$ NMR spectra were recorded on a Varian $400 \mathrm{MR}$ spectrometer, using DMSO- $d_{6}$ as a solvent and TMS as an internal standard. FTIR spectra were recorded on an Avatar 330 FTIR Thermo Nicolet spectrometer from 
samples in Nujol mulls. HPLC/MS analyses were performed on a Waters Alliance 2690 chromatograph. The stationary phase was Atlantis ${ }^{\circledR}$ HILIC silica $(2.1 \times 150$ $\mathrm{mm}$, particle size of the sorbent $3 \mu \mathrm{m}$ ). The mobile phase was water/methanol $(3: 7 ; \mathrm{v} / \mathrm{v})$ at a flow rate of 0.2 $\mathrm{mL} / \mathrm{min}$ at $30^{\circ} \mathrm{C}$. The detector was a Micromass ${ }^{\circledR}$ Quattro Micro $^{\text {TM }}$ API mass spectrometer with electrospray ionization. The water (moisture) content of the ILs was measured by the Karl-Fischer method using a Metrohm 836 Titrant Karl-Fischer titrator, cylinder volume $20 \mathrm{~mL}$. The reagent Hydranal-Composite 5 and the data-processing program Tiamo (version 1.2.1) were used in these analyses. The Karl-Fischer titrator was calibrated with distilled water before each measurement series. The polarity of ILs was evaluated (and $E_{T}^{N}$ calculated) according to a described [20] method using Reichardt's dye and a Perkin-Elmer Lambda 25 UV/Vis spectrophotometer. Data were processed with the program Lambda 25 UV Win Lab. Thermo-gravimetric analysis (TGA) was performed on an SII Extar6000 TG/DTA6300 instrument at a heating rate of $10^{\circ} \mathrm{C} / \mathrm{min}$. The curves showed a sharp decline at around $150^{\circ} \mathrm{C}$. Complete mass loss was observed at temperatures $\geq 300^{\circ} \mathrm{C}$.

Toxicity tests on the IL solutions were performed as described in the Instructions for Users [13]. Rotifers Brachionus calyciflorus, which are part of the consumers trophic level of the aquatic food chain, were used as test organisms [14]. Each sample was analyzed in triplicate using a Toxicity Screening Test Rotoxkit $\mathrm{F}^{\mathrm{TM}}$. Mortality after $24 \mathrm{~h}$ was used as the end-point for determination of acute toxicity. The dilution series to be tested in the definitive test spanned the range from the lowest concentration producing $100 \%$ mortality to the highest concentration producing $0 \%$ mortality in the range of test sensitivity. $\mathrm{LC}_{50}$ values were determined by a graphical interpolation procedure and are expressed in $\mathrm{mg} / \mathrm{L}$.

Chemical oxygen demand was measured according to the European Standard method [13]. Solutions of the ILs in water were oxidized in an acidic $\left(\mathrm{H}_{2} \mathrm{SO}_{4}\right)$ medium with $\mathrm{K}_{2} \mathrm{Cr}_{2} \mathrm{O}_{7}$ at $145^{\circ} \mathrm{C}$ in the presence of $\mathrm{Ag}_{2} \mathrm{SO}_{4}$ and $\mathrm{HgSO}_{4}$, with subsequent spectrophotometric determination of the $\mathrm{Cr}^{3+}$ concentration by means of a spectrophotometer.

Biological oxygen demand was measured according to the European Standard method [14]. A solution of an IL was diluted with the requisite amount of water to obtain an IL concentration of $2 \mathrm{mg} / \mathrm{L}$. Sludge as inoculum was added to the solution. The sample was kept at $20 \pm 1{ }^{\circ} \mathrm{C}$ in darkness in a completely filled and tightly closed vessel in a thermostat for an incubation period of 5 days. The content of dissolved oxygen was measured at the start and at the end of the incubation period by using a WTN 340i/SET oximeter and is expressed in $\mathrm{mg} \mathrm{O}_{2} / \mathrm{L}$.
Biodegradation of the ILs was calculated as the ratio of biologically and chemically consumed oxygen. Glucose/ glutamic acid mixture was used as a reference material.

\section{Acknowledgements}

The authors are grateful to the European Social Fund for financial support of this research.

\section{References}

[1] P. Wasserscheid and T. Welton, "Ionic Liquids in Synthesis," 2nd Edition, Vol. 1, Wiley-VCH, Weinheim, 2008.

[2] N. Gathergood, M. T. Garcia and P. J. Scammells, "Biodegradable Ionic Liquids: Part I. Concept, Preliminary Targets and Evaluation," Green Chemistry, Vol. 6, No. 3, 2004, pp. 166-175. doi:10.1039/b315270g

[3] M. T. Garcia, N. Gathergood and P. J. Scammells, "Biodegradable Ionic Liquids. Part II. Effect of the Anion and Toxicology," Green Chemistry, Vol. 7, No. 1, 2005, pp. 9-14. doi:10.1039/b411922c

[4] N. Gathergood, P. J. Scammells and M. T. Garcia, "Biodegradable Ionic Liquids. Part III. The First Biodegradable Ionic Liquid," Green Chemistry, Vol. 8, No. 2, 2006, pp. 156-160. doi:10.1039/b516206h

[5] D. Coleman and N. Gathergood, "Biodegradation Studies of Ionic Liquids," Chemical Society Reviews, Vol. 39, No. 2, 2010, pp. 600-637. doi:10.1039/b817717c

[6] M. Stasiewicz, E. Mulkiewicz, R. Tomczak-Wandzel, J. Kumirska, E. M. Siedlecka, M. Gołebiowski, J. Gajdus, M. Czerwicka and P. Stepnowski, "Assessing Toxicity and Biodegradation of Novel, Environmentally Benign Ionic Liquids (1-Alkoxymethyl-3-Hydroxypyridinium Chloride, Saccharinate and Acesulfamates) on Cellular and Molecular Level," Ecotoxicology and Environmental Safety, Vol. 71, No. 1, 2008, pp. 157-165. doi:10.1016/j.ecoenv.2007.08.011

[7] A. Romeroa, A. Santos, J. Tojob and A. Rodríguez, “Toxicity and Biodegradability of Imidazolium Ionic Liquids," Journal of Hazardous Materials, Vol. 151, No. 1, 2008, pp. 268-273. doi:10.1016/j.jhazmat.2007.10.079

[8] N. Bicak, "A New Ionic Liquid: 2-Hydroxyethylammonium Formate," Journal of Molecular Liquids, Vol. 116, No. 1, 2005, pp. 15-18. doi:10.1016/j.molliq.2004.03.006

[9] L. Zhai, Q. Zhong, C. He and J. Wang, "Hydroxyl Ammonium Ionic Liquids Synthesized by Water-Bath Microwave: Synthesis and Desulfurization," Journal of Hazardous Materials, Vol. 177, No. 1-3, 2010, pp. 807-813. doi:10.1016/j.jhazmat.2009.12.105

[10] Rotoxkit $\mathrm{F}^{\mathrm{TM}}$, "Freshwater toxicity test with a ciliateprotozoan. Standard Operational Procedure," Creasel, Deinze, Belgium, 1998, p. 18.

[11] Ch. Belgis and P. Guido, "Cyst-Based Toxicity Tests. XI. Influence of the Type of Food on the Intrinsic Growth Rate of the Rotifer Brachionus calyciflorus in ShortChronic Toxicity Tests," Chemosphere, Vol. 50, No. 3, 
2003, pp. 365-372. doi:10.1016/S0045-6535(02)00496-4

[12] J. L. Zurita, G. Repetto, A. Jos, A. del Peso, M. Salguero, M. López-Artkguez, D. Olano and A. Camein, "Ecotoxicological Evaluation of Diethanolamine Using a Battery of Microbiotests," Toxicology in Vitro, Vol. 19, No. 7, 2005, pp. 879-886. doi:10.1016/j.tiv.2005.06.035

[13] ISO 15705:2000, "Determination of the Chemical Oxygen Demand Index (ST-COD)-Small-Scale SealedTube Method."

[14] ISO 5815:1989, "Water Quality-Determination of BioChemical Oxygen Demand after 5 Day $\left(\mathrm{BOD}_{5}\right)$ - Dilution and Seeding Method."

[15] J. Zabicky, "The Kinetics and Mechanism of CarbonylMethylene Condensation Reactions. Part XI. Stereochemistry of the Products," Journal of the Chemical Society, Vol. 137, No. 0, 1961, pp. 683-687. doi:10.1039/jr9610000683

[16] M. G. Ahmed, U. K. R. Romman, S. M. Ahmed, K. Akhter and M. E. Halim, "Synthesis and Correlation of Spectral Properties of Some Substituted 1,3-Diphenyl-2Propen-1-Ones," Bangladesh Journal of Scientific and Industrial Research, Vol. 42, No. 1, 2007, pp. 45-52. doi:10.3329/bjsir.v42i1.354

[17] S. Keskin, D. Kayrak-Talay, U. Akman and Ö. Hortaçsu, "A Review of Ionic Liquids towards Supercritical Fluid
Applications," The Journal of Supercritical Fluids, Vol. 43, No. 1, 2007, pp. 150-180. doi:10.1016/j.supflu.2007.05.013

[18] A. Zicmanis, S. Pavlovica, E. Gzibovska, P. Mekss and M. Klavins, "2-Hydroxyethylammonium CarboxylatesHighly Biodegradable and Slightly Toxic Ionic Liquids," Latvian Journal of Chemistry, Vol. 3, No. 4, 2010, pp. 269-275.

[19] A. Zicmanis, S. Pavlovica, E. Gzibovska and P. Mekss, "2- Hydroxyethylammonium Carboxylates - Catalysts and Reaction Media for Condensation Reactions," Innovations and Technologies News, Vol. 2, No. 7, 2010, pp. 3-10.

[20] C. Reichardt, "Polarity of Ionic Liquids Determined Empirically by Means of Solvatochromic Pyridinium N-Phenolate Betaine Dyes," Green Chemistry, Vol. 7, No. 5, 2005, pp. 339- 351. doi:10.1039/b500106b

[21] A. I. Vogel, "A Textbook of Practical Organic Chemistry Including Quantitative Organic Analysis," 3rd Edition, Longmans, London, 1961, p. 718.

[22] J. R. Harjani, J. Farrell, M. T. Garcia, R. D. Singer and P. J. Scammells, "Further Investigation of the Biodegradability of Imidazolium Ionic Liquids," Green Chemistry, Vol. 11, No. 6, 2009, pp. 821-829. doi:10.1039/b900787c 